07

\title{
Исследование процесса выключения интегрального тиристора с внешним полевым управлением
}

\author{
(С) И.В. Грехов, ${ }^{1}$ А.Г. Люблинский, ${ }^{1}$ А.А. Скиданов ${ }^{2}$ \\ ${ }^{1}$ Физико-технический институт им. А.Ф. Иофрфе РАН, \\ 194021 Санкт-Петербург, Россия \\ ${ }^{2}$ ЗАО „ВЗПП-Микрон“, \\ 394033 Воронеж, Россия \\ e-mail: grekhov@mail.ioffe.ru
}

(Поступило в Редакцию 14 июня 2016 г.)

\begin{abstract}
Представлены результаты экспериментального исследования процесса выключения интегрального тиристора в схеме с индуктивной нагрузкой. Показано, что предельная плотность выключаемого тока определяется возникновением высокочастотного колебательного процесса в условиях динамического лавинного пробоя, приводящего к образованию нестабильных шнуров тока. Этот процесс возникает в самом начале нарастания напряжения на коллекторном переходе и инициируется потоком электронов из эмиттера в область объемного заряда коллектора. Обсуждены возможные пути повышения предельной плотности выключаемого тока.
\end{abstract}

DOI: 10.21883/JTF.2017.01.44034.1930

\section{Введение}

Интегральный тиристор - это прибор силовой микроэлектроники на основе кремниевой тиристорной $n^{+} p^{\prime} N_{0} p^{+}$-структуры, эмиттерный $n^{+} p^{\prime}-$ переход которого выполнен в виде узких сильнолегированных $n^{+}$полос с поперечным размером $\sim 15 \mu$, а $p^{\prime}$-базовый слой с уровнем легирования $10^{16}-10^{17} \mathrm{~cm}^{-3}$ имеет толщину $2-3 \mu$, т.е. быстродействие и коэффициент усиления $n^{+} p^{\prime} N_{0}$-транзистора довольно высокие. Толщина и уровень легирования $N_{0}$-базового слоя, как и в обычном тиристоре, выбираются в зависимости от требуемой величины рабочего напряжения. Эмиттерные и базовые полосы, длина которых около $100 \mu$, объединены алюминиевыми шинами с шириной $\sim 100 \mu$. Эмиттерные шины объединяются шиной шириной $\sim 400 \mu$, к которой осуществляется приварка контактных выводов. Базовые шины соединяются с контактными площадками, к которым также производится приварка выводов. Толщина алюминиевой металлизации эмиттерных и базовых полос составляет $\sim 2 \mu$, а на шины наносится второй слой металлизации толщиной $\sim 6 \mu$. Защита от пробоя по поверхности коллекторного $p^{\prime} N_{0}$-перехода осуществляется системой охранных колец. В ЗАО ВЗПП-Микрон были разработаны три типоразмера чипов интегральных тиристоров $5.1 \times 4.45$ (тестовый чип), $10.8 \times 9.5$ и $13.5 \times 13.5 \mathrm{~mm}^{2}$. Конструкция тестового чипа показана на рис. 1 , а поперечное сечение элементарной ячейки и упрощенная схема подключения чипа для исследования процесса выключения с индуктивной нагрузкой показана на рис. 2, рабочая площадь чипа $8.6 \mathrm{~mm}^{2}$, блокируемое напряжение $3300 \mathrm{~V}$.

Включение интегрального тиристора (ИТ) производится, как и обычного тиристора, пропусканием короткого импульса прямого тока в цепи АВ эмиттербаза. Малая ширина эмиттерных и базовых полос и равномерное распределение их по рабочей площади прибора обеспечивает одновременное переключение всей площади, что позволяет коммутировать ток с большой плотностью и высокой скоростью нарастания. Распределение концентрации электронно-дырочной плазмы во включенном состоянии схематически показано в левой части рис. 2. Процесс включения был довольно подробно исследован в [1 и 2].

Выключение ИТ обычно производится путем замыкания цепи эмиттер-база внешним полевым транзистором с малым сопротивлением канала, в наших экспериментах использовался транзистор IRLR7833PBF с сопротивлением канала $4.5 \mathrm{~m} \Omega$.

Типичная осциллограмма процесса выключения при напряжении на приборе $400 \mathrm{~V}$ и токе $6 \mathrm{~A}$ приведена на рис. $3, a$, измерение полного тока и тока в цепи эмиттера производились с помощью измерительного трансформатора тока. Хорошо видно, что спад эмиттерного тока начинается сразу после подачи импульса управления и включения полевого транзистора, но полный ток, поддерживаемый индуктивностью $L$, остается постоянным, а ток из эмиттерной цепи постепенно переходит в цепь базы. Через $200 \mathrm{~ns}$ напряжение на приборе начинает нарастать, т.е. $p^{\prime}$-база освобождается от электроннодырочной плазмы и у коллектора образуется область объемного заряда (ОО3). В следующие $100 \mathrm{~ns}$ ток через ООЗ переносится свободными электронами, инжектируемыми из эмиттера, и дырками, выносимыми из электронно-дырочной плазмы, затем эмиттер запирается и ток через ОО3 становится чисто дырочным. Вынос дырок из плазмы сопровождается расширением ООЗ и ростом напряжения на приборе. Необходимо отметить, что вынос дырок не уменьшает общего количества запасенной плазмы в $N_{0}$-базе, поскольку соответствующее количество дырок инжектируется в эту базу из $p^{+}$-эмиттера. Через $550 \mathrm{~ns}$ после начала процесса вы- 


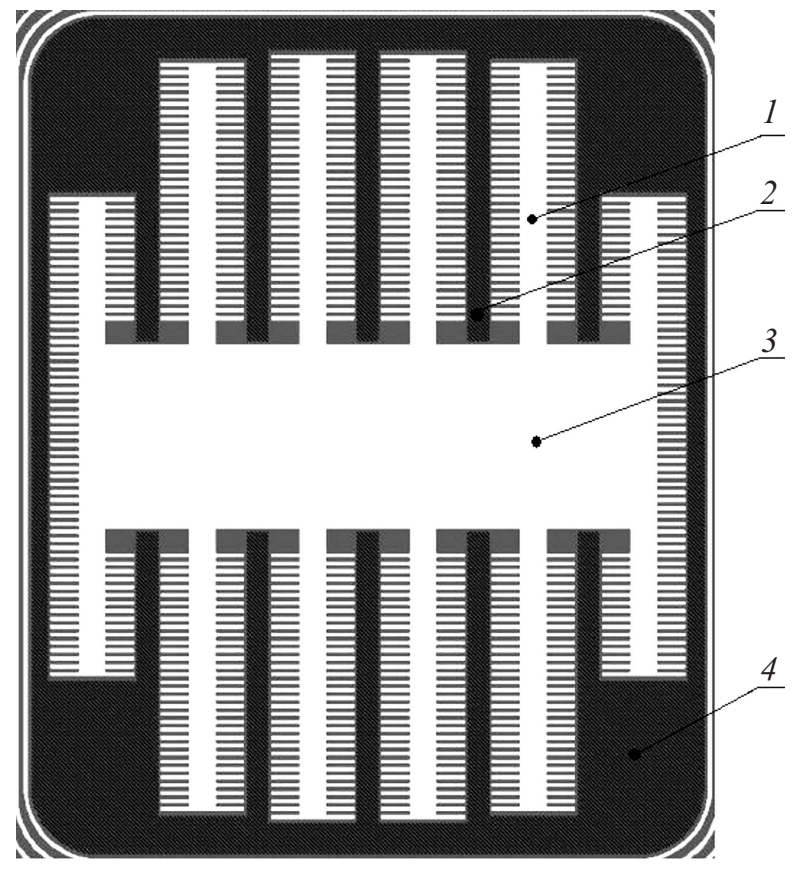

Рис. 1. Конструкция тестового чипа: 1 - эмиттерная шина шириной $100 \mu, 2$ - базовая шина шириной $100 \mu$, 3 - эмиттерная шина шириной $400 \mu, 4-$ базовая контактная площадка.

ключения напряжение на аноде тиристора возрастает до напряжения источника питания и ток, поддерживаемый индуктивностью, замыкается через прямосмещенный диод $D$, спадая в цепи ИТ.

При увеличении амплитуды выключаемого тока до 9.6 А при неизменном рабочем напряжении возникает высокочастотный колебательный процесс (рис. $3, b$ ) на осциллограммах эмиттерного и полного токов, при дальнейшем незначительном повышении выключаемого тока прибор разрушается. Такой колебательный процесс неоднократно наблюдался ранее $[3,4]$ и др. при прохождении потока свободных носителей из плазмы через ООЗ обратносмещенного $p n$-перехода как в диодных, так и более сложных структурах, например в IGBT. При высокой плотности носителей в ОО3 создаваемое ими поле вызывает нестабильный во времени и пространстве динамический лавинный пробой и образование нестабильных шнуров тока. Наши эксперименты показали, что предпробойный колебательный процесс развивается при примерно одинаковом выключаемом токе в широком диапазоне напряжений от 250 до $1200 \mathrm{~V}$, т.е. квазистатическое поле в ООЗ обратносмещенного коллектора гораздо меньше влияет на развитие динамического пробоя, чем поле свободных носителей, проходящих через ООЗ.

Осциллограмма разрушающего процесса при токе $\sim 10$ А и напряжении $1200 \mathrm{~V}$ показана на рис. 4. После замыкания цепи эмиттер-база полевым транзистором эмиттерный ток падает до $\sim 2 \mathrm{~A}$, а затем возникает нарастающий колебательный процесс, приводящий к разрушению прибора.

Плотность тока, разрушающего прибор при выключении, равна $\sim 120 \mathrm{~A} / \mathrm{cm}^{2}$.

На приведенных осциллограммах спада силового тока видно, что колебания тока возникают в самом начале нарастания напряжения, когда ширина ОO3 еще сравнительно невелика, а плотность потока электронов, инжектируемых из $n^{+}$-эмиттера еще довольно большая.

Скорее всего, именно электроны ответственны за возникновение динамического лавинного пробоя, поскольку коэффициент ионизации у них значительно больший, чем у дырок. В этом случае предельную плотность выключаемого тока можно увеличить, если обеспечить существенное уменьшение инжекции электронов из $n^{+}$эмиттера раньше, чем начнется нарастание напряжения на приборе и образование ОО3 у коллектора. Для этого необходимо обеспечить высокую скорость спада эмиттерного тока, которая может быть достигнута путем уменьшения паразитной индуктивности цепи, замыкающей эмиттерную и базовые шины. Эта цепь состоит из катодных и базовых выводов тиристорного чипа, полевого транзистора и коротких соединительных шин. В исследованной тестовой схеме паразитная индуктивность замыкающей цепи была снижена насколько возможно и, по нашим оценкам, составила $20 \mathrm{nH}$. К сожа-

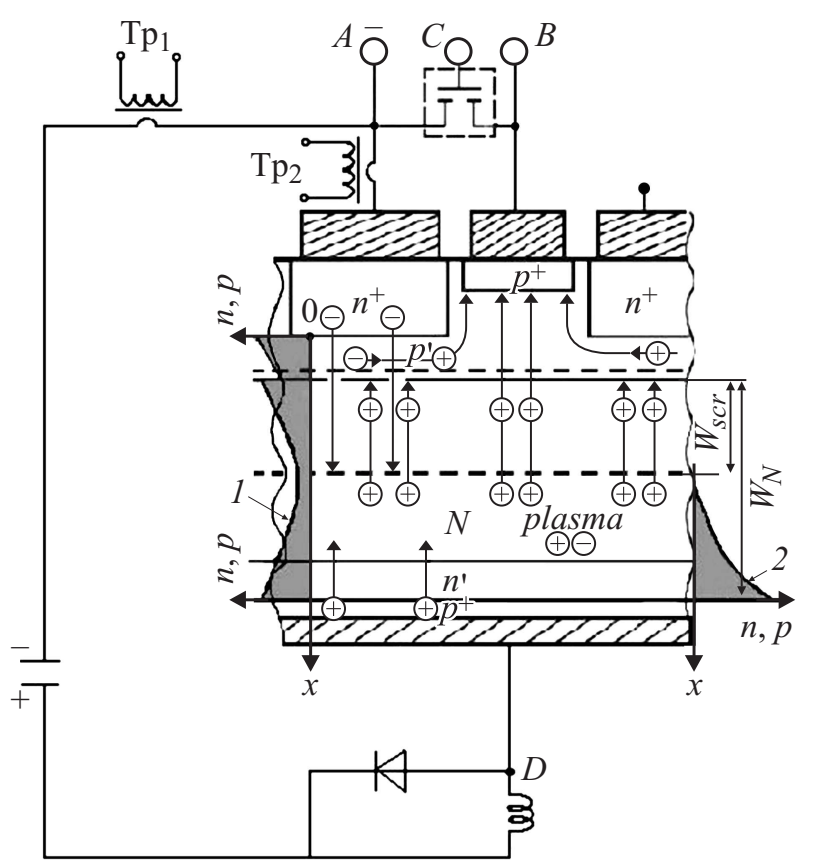

Рис. 2. Поперечное сечение тиристорной ячейки и принципиальная схема установки для исследования процесса выключения: 1 - распределение концентрации электронно-дырочной плазмы в базовых $p^{\prime}$ - и $N n^{\prime}$-областях тиристора во включенном состоянии, 2 - распределение концентрации плазмы в конце процесса выключения, стрелками показано направление движения электронов $\ominus$ и дырок $\ominus$ в процессе выключения. $T_{p 1}, T_{p 2}$ - измерительные трансформаторы тока в силовой цепи и цепи эмиттера соответственно. 


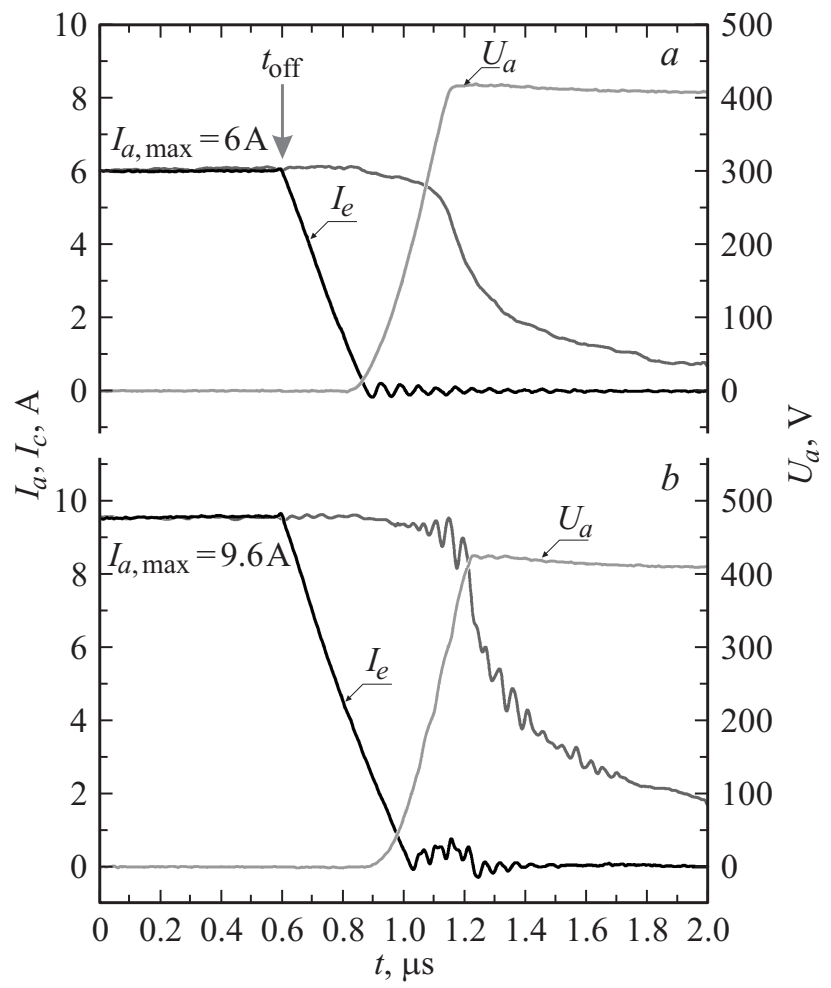

Рис. 3. $a-$ осциллограммы процесса выключения при начальном токе в 6 А и напряжении на конденсаторе $400 \mathrm{~V}$; $b$ - осциллограммы процесса выключения при токе $9.4 \mathrm{~A}$, близком к предельному и напряжении $400 \mathrm{~V}$. $I_{a}$ - анодный ток, $I_{e}$ - ток в цепи эмиттера, $U_{a}-$ напряжение на приборе. Стрелкой показан момент включения полевого транзистора.

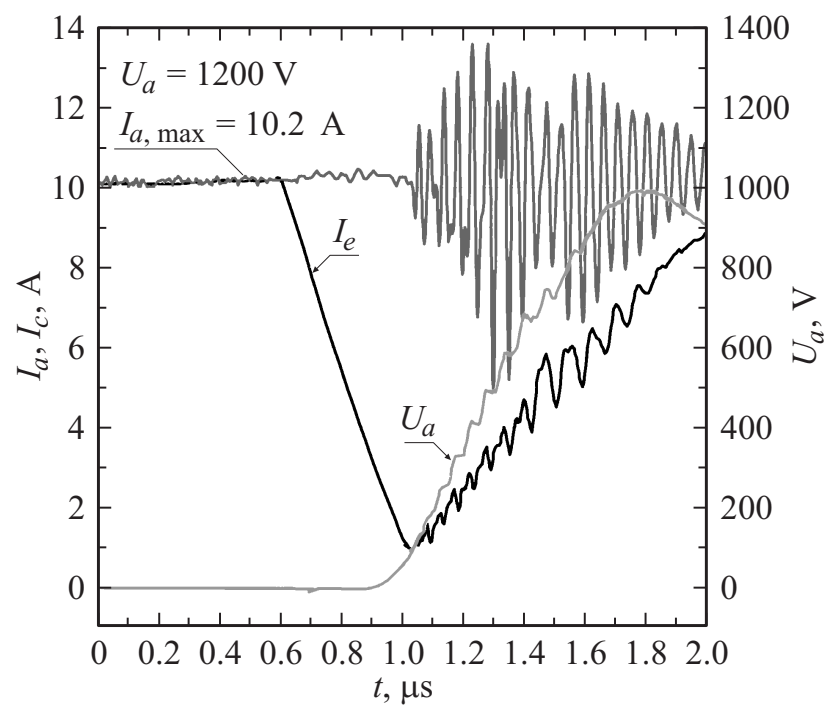

Рис. 4. Осциллограмма разрушающего процесса выключения при токе $\sim 10 \mathrm{~A}$ и напряжении $1200 \mathrm{~V}: I_{a}-$ анодный ток, $I_{e}-$ ток в цепи эмиттера, $U_{a}$ - напряжение на приборе.

лению, при существующей конструкции чипа существенное уменьшение этой индуктивности не представляется возможным.
Увеличить плотность выключаемого тока можно также путем задержки нарастания напряжения на коллекторе при спаде эмиттерного тока с помощью относительно небольшой емкости (снаббера), включенного параллельно тиристорной структуре. На рис. 5 приведены предельные (предпробойные) осциллограммы процесса выключения тестовой структуры при величине снабберной емкости 470 и $940 \mathrm{pF}$. Замедление нарастания напряжения позволило увеличить предельную величину выключаемого тока с 9.6 до 9.9 А при $C=470 \mathrm{pF}$ и до 10.5 А при $940 \mathrm{pF}$.

Таким образом, экспериментальное исследование процесса выключения интегрального тиристора путем замыкания цепи эмиттер-база полевым транзистором показало, что основным явлением, ограничивающим плотность выключаемого тока, является динамический лавинный пробой в ООЗ коллекторного перехода, вызывающий высокочастотные колебания силового тока и его шнурование. Этот процесс развивается в самом начале нарастания напряжения на коллекторном переходе, когда ширина ОО3 еще сравнительно невелика, а плотность потока электронов, инжектируемых из $n^{+}$-эмиттера, еще довольно большая. Поэтому предельно-допустимая плотность выключаемого тока практически не зависит от величины напряжения на приборе после выключения.

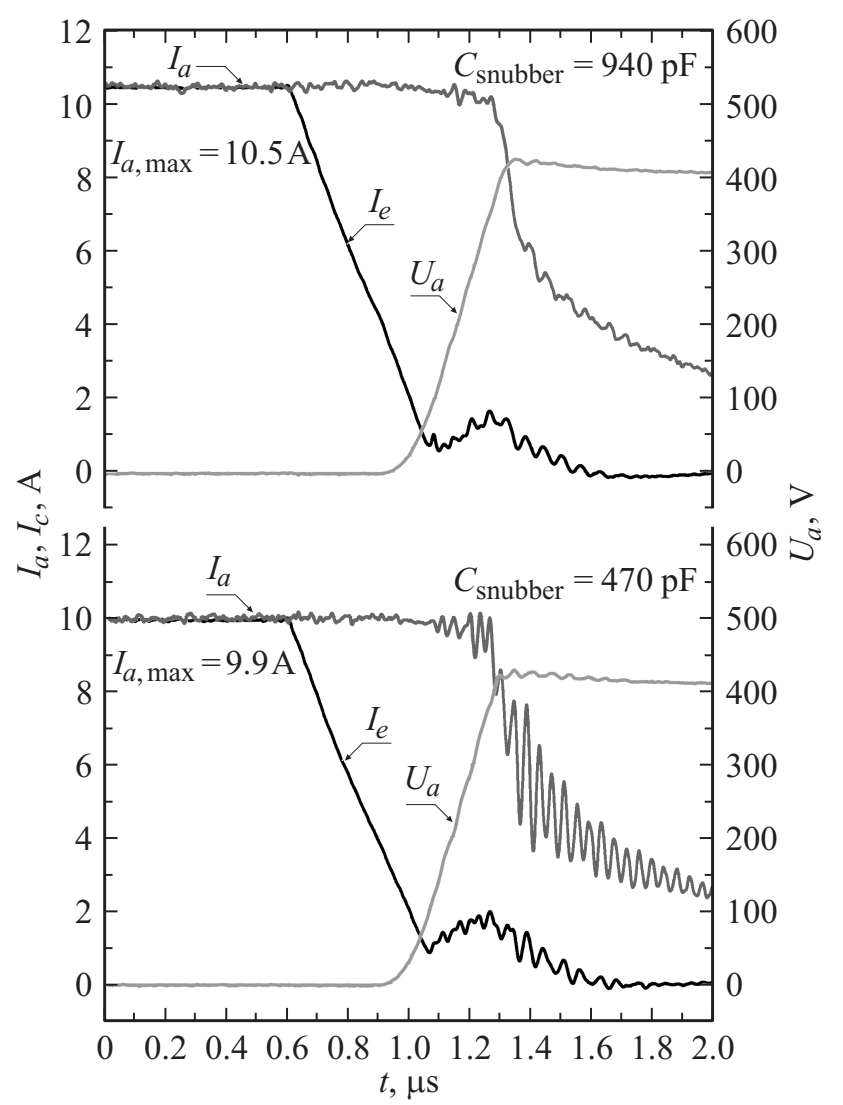

Рис. 5. Осциллограмма процесса выключения с шунтирующей емкостью (снаббером): $I_{a}-$ анодный ток, $I_{e}-$ ток в цепи эмиттера, $U_{a}$ - напряжение на приборе. 
Для увеличения предельной плотности выключаемого тока необходимо существенно уменьшить, или вообще прекратить, инжекцию электронов из $n^{+}$-эмиттера до начала нарастания напряжения на приборе и образования OO3 у коллектора.

\section{Список литературы}

[1] Грехов И.В., Жмодиков А.Л., Коротков С.В. // ПТЭ. 2015. № 1. C. $1-3$.

[2] Грехов И.В., Жмодиков А.Л., Коротков С.В., Прижимов С.В., Фоменко Ю.Л. // ПТЭ. 2016. № 3. С. 32-36.

[3] Domeij M., Lutz J., Silber D. // IEEE Trans. Electron. Devises. Vol. 50. N 2. P. 486-493.

[4] Rose P., Silber D., Porst A., Pfirch F. Ivestigation on the stability of dynamic avalanche in IGBTs. Proceedings of the ISPSD. 2002. 